\title{
COMUNICACIÓN/COMMUNICATION
}

\section{LA CRISIS DE LA PRENSA EN ESPAÑA: ANÁLISIS DEL CASO PÚBLICO, UN DIARIO NACIDO A CONTRACORRIENTE}

Manuel Fernández-Sande': Universidad Complutense de Madrid. España manuel.fernandez@ccinf.ucm.es

\section{RESUMEN}

Público representa el último intento empresarial de incorporar un diario de información general al mercado de la prensa escrita en España. La breve historia del periódico (2007-2012) coincide con el periodo más recesivo del sector. El diario, vinculado al grupo multimedia liderado por el empresario Jaume Roures, pretendía convertirse desde un posicionamiento ideológico de izquierdas, en un referente informativo de calidad. El análisis de las diferentes variables endógenas - diseño y contenidos informativos, evolución de su difusión y audiencia, gestión comercial, estrategia de distribución, configuración de la estructura organizativa-; así como exógenas -principalmente determinadas por la dinámica del sector y la crisis económica- permiten un mejor conocimiento de lo que supuso este proyecto periodístico.

PALABRAS CLAVE: Empresa informativa - Crisis de la prensa - Medios de Comunicación - Periodismo - Público - Mediapubli

\footnotetext{
${ }^{1}$ Autor correspondiente:

Manuel Fernández-Sande: Profesor Contratado Doctor de la Facultad Ciencias de la Información de la Universidad Complutense de Madrid. España.

Correo: manuel.fernandez@ccinf.ucm.es
} 


\title{
THE CRISIS OF THE PRESS IN SPAIN: ANALYSIS OF THE PÚBLICO CASE, A NEWSPAPER BORN UPSTREAM
}

\begin{abstract}
Público represents the latest business attempt to incorporate a general daily newspaper to the market of written press in Spain. The brief history of this newspaper (2007-2012) coincides with the most recessive period of this sector. The newspaper, belonging to the multimedia group led by businessman Jaume Roures, tried to be, from a left-wing position, a top-quality information reference. The analysis of the various internal variables - design and information content, difusion and audience evolution, commercial management, distribution strategy, configuration of the organizational structure; and also external variables - especially determined by the dynamics of the sector and the economic crisis - allows for a better understanding of what was intended with this journalistic project.
\end{abstract}

KEY WORDS: Media Company - Crisis of the press - Mass Media - Journalism Público - Mediapubli

\section{INTRODUCCIÓN}

Con el cierre de la versión en papel de Público el 24 de febrero de 2012, finalizaba la última iniciativa de incorporar al mercado español un diario de información general de pago. La aventura periodística de Público ha durado algo menos de cuatro años y medio, cincuenta y tres meses de una actividad empresarial cuya corta historia se ha caracterizado por un continuo intento de consolidar una oferta informativa a contracorriente.

La decisión del lanzamiento del periódico, se produce en plena transición entre unos años de importante prosperidad económica en el sector, con un progresivo aumento de la inversión publicitaria, cuyo techo histórico se produce precisamente en el ejercicio de 2007 -año del lanzamiento del diario-, con cerca de 1.900 millones de euros de facturación publicitaria en España según Infoadex. (INFOADEX, 2012) Una cifra que desde ese año no ha parado de descender hasta los 967 millones de euros de ingresos por publicidad, registrados por los diarios españoles en 2011. Por tanto, durante la existencia de Público los ingresos publicitarios de la prensa descendieron en su conjunto en un $49 \%$.

En el año 2007, la inversión publicitaria en los diarios finalizaba un ciclo alcista de cinco ejercicios consecutivos, en los que el crecimiento de la inversión desde el año 2003 se aproximó al 30\%. Con anterioridad se había producido una ligera recesión publicitaria entre 2000 y 2003 del 12\%. La crisis publicitaria que ha golpeado a los diarios entre 2007 y 2012, es consecuencia directa de la crisis económica y de la migración de las audiencias a soportes digitales. El plan de negocio del diario en 
ningún caso tuvo en cuenta un escenario tan hostil, ante el que resultaba casi imposible obtener una viabilidad económica. Algunos errores estratégicos y de gestión, que repasaremos en este trabajo, agravarían la posición económica de la empresa editora.

En lo que se refiere a la difusión total de los diarios de información general, los años de Público (2007-2011) se corresponden con un descenso del 8,5\% según OJD. Si analizamos los datos de algunos diarios, competencia directa de Público en su ámbito de difusión nacional, podemos comprobar que la venta de periódicos de El País y El Mundo descendió en estos años un 16\% y un 24\% respectivamente. (AEDE, 2012)

Tras este análisis sectorial es posible afirmar que Público nació en el peor momento posible de las últimas décadas. Es cierto que ningún editor de periódicos logró prever el rápido deterioro que iba a sufrir la prensa en estos años, pero en 2007 sí existían algunas tendencias que ya se podían observar con cierta claridad.(Larrañaga, 2009) Farias y Roses argumentan que el modelo de negocio de los medios informativos ya estaban en crisis antes de la recesión económica-financiera internacional que habría actuado como un acelerador del proceso. (Farias y Roses, 2009) Cuando Jaume Roures, Tatxo Benet y Gerard Romy deciden poner en marcha junto a otros socios la iniciativa de un diario de información general, la reconversión del sector ya estaba en marcha. La crisis económica y la recesión publicitaria aceleran el deterioro financiero de las empresas editoras, pero el proceso de transformación de la industria de la prensa se había iniciado ya en 2007. La consolidación de los diarios gratuitos de información general en las principales capitales, y la migración de lectores hacia las versiones digitales de los propios periódicos, provocaron un estancamiento y posteriormente un retroceso de las ventas de periódicos en la mayoría de los países de nuestro entorno. Ignacio Ramonet también apuntaba a la pérdida de credibilidad como una causa interna de la crisis de la prensa (Ramonet, 2005). Las estrategias empresariales y comerciales del sector han tenido un impacto negativo en la propia profesión periodística y han provocado un debilitamiento de los principios esenciales que deberían regir la actividad informativa de los medios (Rodríguez-Polo y MartínAlgarra, 2011).

Las editoras confiaron que la difusión de diarios en papel no se vería afectada de un modo tan directo por las nuevas formas de consumo en Internet, pero la convergencia multimedia ha implicado cambios profundos en las cuatro dimensiones: la empresarial, la tecnológica, la profesional y la comunicacional. (Salaverria, 2003). Los editores de diarios desplegaron en la Red estrategias conservadoras, siempre reactivas ante el empuje de los nuevos medios pero con escasa visión de futuro y de nuevas perspectivas de negocio. (Boczkowski, 2006) Sánchez Tabernero señala una serie de factores determinantes: "desarrollo tecnológico, incremento de la competencia y mayor hábito de elección de los ciudadanos" en la transformación que viven los medios de comunicación y su oferta de contenidos. (Sánchez Tabernero, 2008)

Los grandes grupos periodísticos iniciaron procesos de cambio, impulsados por la evolución tecnológica y las nuevas demandas de información interactiva. Las 
empresas trataron de desarrollar modelos de negocio basados en una convivencia de la prensa en papel y digital, pero se comenzaba a vislumbrar un futuro en el que prevalecerían las versiones digitales de los diarios. Por eso, la decisión de lanzar Público en papel tras casi diez años desde la salida de La Razón -en aquel momento última cabecera de pago de información general que había entrado en el mercado-, supuso una gran sorpresa para el sector.

\section{ANÁLISIS Y DISCUSIÓN}

\subsection{Orígenes del proyecto periodístico}

La empresa Mediapubli, Sociedad de Publicaciones y Ediciones S.L., inició sus operaciones en febrero de 2007, según estatutos con el siguiente objeto social: "La edición, impresión, distribución y venta por cuenta propia o ajena de impresos de periódicos, semanarios y toda clase de publicaciones periódicas". El capital social suscrito fue de 1.453.060 Euros. ${ }^{2}$ La iniciativa partía de un grupo de empresarios de comunicación que en los últimos años había alcanzado un gran protagonismo en el sector audiovisual a través de Mediapro y Gestora de Inversoras Audiovisuales La Sexta S.A., adjudicataria en 2005 de una licencia de televisión. En esos años la empresa propietaria de La Sexta contaba con la participación accionarial de un consorcio de productoras de contenidos entre los que destacaba Mediapro y el Grupo Imagina. También estaba participada en un $40 \%$ por Televisa y otros accionistas minoritarios como diversos fondos de capital riesgo. Entre 2005 y 2007 el grupo emprende una dura pugna empresarial por la consecución de diferentes derechos de retransmisiones deportivas, que desembocará en la llamada guerra del futbol con PRISA y una de sus empresas SOGECABLE. (García Chamizo, 2009)

El objetivo de Jaume Roures y sus socios más próximos Tatxo Benet y Gerrard Romy, fue construir un gran grupo multimedia que debería incluir un periódico de información general con capacidad de influencia política. Algunos de los socios participantes en el capital de Gestora de Inversoras Audiovisuales La Sexta decidieron no entrar en el nuevo proyecto al no considerar estratégica esta inversión e incluso, en algunos casos, ser valorada de forma negativa ante las posibles consecuencias que tendría una vinculación con un medio escrito de un rotundo posicionamiento ideológico.

Mediapubli Sociedad de Publicaciones y Ediciones S.L. fue la empresa constituida con el fin de explotar el nuevo periódico. Se configuró con un capital dividido en una red de sociedades sin conexión directa con ninguna de las empresas del grupo en el sector audiovisual. El capital social de Mediapubli quedó distribuido de la siguiente forma: Orpheus Media (52,30\%), Multiax Invera (16,52\%), Mentaema SL $(9,9 \%)$, Mediavideo SL $(1,10 \%)$, Mediacable Servicios de Producción S.L (12,80\%), Grupo Metis S.A. $(0,24 \%)$, Política, Internet y Sociedad S.L. $(0,24 \%)$ e Inversoras Editoriales Panamericanas S.L $(6,88 \%)$.

\footnotetext{
${ }^{2}$ Información mercantil de Mediapubli Sociedad de Publicaciones y Ediciones S.L. Fuente: Registro Mercantil Barcelona
} 
Los empresarios que lideraron el proyecto fueron Jaume Roures y Tatxo Benet. Desde verano de 2007 se comenzó a configurar la redacción del periódico, y desde meses atrás ya se trabajaba en el concepto del nuevo diario. El estudio Cases i Associats se encargó de realizar el diseño de un nuevo periódico "popular, independiente, radicalmente democrático, respetuoso, plural, crítico, muy riguroso, joven y moderno", según fue presentado al resto de medios por el propio Tatxo Benet. ${ }^{3}$

En esa misma rueda de prensa, Jaume Roures afirmó que el nacimiento del periódico surgía como una obligación por la vocación multimedia de su proyecto empresarial, y por la gran influencia social que posee la prensa escrita, que de esa forma podría fortalecer internamente a su grupo.

El posicionamiento ideológico del periódico se definía como un diario comprometido con la izquierda y plural. Un producto innovador con capacidad de renovar el mercado y diferente a la oferta del momento.

Roures en su intervención señalaba las que consideraba algunas de las claves del futuro del diario:

"nuestra base de partida es esa conjunción de la gente que se incorpora a la lectura que por suerte es mucha, de la gente que la prensa gratuita ha animado a leer cotidianamente y de la gente que tiene aparte de su periódico de referencia otras inquietudes y es comprador de un segundo periódico" ${ }^{\prime \prime}$.

En las fechas del lanzamiento de Público, el mercado de la prensa de información general era clasificado como un mercado muy maduro y estancado, incluso a pesar de las agresivas campañas de promociones comerciales aplicadas por los principales diarios. (Edo, 2005) Sin embargo, los empresarios editores de Público partían de la idea de una base de lectores que se estaba ampliando, convencidos de que cada periódico que había salido al mercado había encontrado su espacio "no forzosamente a costa de un tercero". Los datos extraídos de los controles de la OJD no confirmaban esta hipótesis, dado que ya en el año 2007 la evolución de la difusión de los diarios de información general desde el año 1999 registraba un descenso del 1\% (AEDE, 2002 y 2012), por tanto no se correspondía en absoluto con una perspectiva tan optimista.

Los empresarios creen identificar una oportunidad de mercado para Público, ante la presencia en el mercado de tres diarios de información general, con difusión nacional, que mantenían una línea editorial que se podría englobar en el segmento ideológico de centro-derecha: EL Mundo, ABC, La Razón -a los que en octubre de 2009 se sumaría La Gaceta-, frente a El País como un único diario de centro-izquierda. Desde un principio se interpretó que Público pretendía ganar lectores de izquierdas descontentos con la línea editorial de El País.

\footnotetext{
${ }^{3}$ Rueda de prensa de presentación del diario Público. Madrid, 20-09-2007. Disponible en: http://www.youtube.com/watch?v=6qGbx9NCsOU [Fecha última consulta 5-06-12]

${ }^{4}$ Rueda de prensa de presentación del diario Público. Madrid, 20-09-2007. Disponible en: http://www.youtube.com/watch?v=6qGbx9NCsOU [Fecha última consulta 5-06-12]
} 
En la prensa del momento, desde algunos medios, se interpreta la salida de Público como un movimiento político del entorno del presidente del gobierno Rodríguez Zapatero, al que se vincula al propio Roures y a otros directivos y propietarios de las sociedades relacionadas con Mediapro.

El primer número del periódico apareció el 26 de septiembre de 2007, con una tirada de 250.000 ejemplares y a 64 páginas. El producto presentaba un diseño bastante diferente a la competencia en el que destaca una doble portada y un uso intensivo del color. Se elige una estrategia de marketing del lanzamiento similar a la que en su día había utilizado La Razón, con un precio de salida de 50 céntimos de euro para ganar lo más rápido posible cuota de mercado. La decisión le traerá dificultades en la distribución, dado que los vendedores de prensa se quejaron del escaso beneficio que obtenían con la venta de este periódico, sensiblemente inferior al que conseguían con la venta de las otras cabeceras, puesto que su ganancia se genera por una comisión respecto al precio de venta final.

\subsection{Posicionamiento ideológico y estrategia informativa}

El estudio del modelo de gestión empresarial de Público resulta de gran interés, porque representa uno de los últimos ejemplos de estrategia expansiva en la prensa. Desde el año 2008 la mayoría de editoras optan por una estrategia competitiva basada en el abaratamiento de costes y drásticos recortes para intentar compensar la caída de ingresos. Público surge a finales del año 2007 como un proyecto lleno de ambición, en el que el modelo de negocio se basa en un intento de ganar cuota de mercado con rapidez, con una campaña agresiva en lo que se refiere a su precio de venta reducido, una distribución de promociones culturales gratis o a muy bajo coste para lograr fidelizar lectores, y un plan de difusión basado en un sistema de distribución masiva en toda España. En definitiva, un intento de crecer rápido para generar ingresos, pero con unos costes de producción y distribución muy elevados.

La redacción fundacional de Público buscaba combinar la juventud de un buen número de redactores con la experiencia y el prestigio de periodistas fichados de diferentes medios. Reclutar a profesionales que en su mayoría ya estaban bien pagados en sus medios de origen implicaba el pago de nominas elevadas para lograr vincularles a un proyecto que todavía era una incógnita. Roures y su equipo buscaban hacer un periódico de calidad, capaz de competir con los grandes diarios españoles, y para ello no reparó en traer a los que consideraba los mejores en diferentes ámbitos: Fernando Garea (El Mundo), Jesús Maraña y Manuel Rico (Tiempo), María Luisa Roselló (Metro), Salome García (Periódico de Cataluña), Patricia Fernández de Lis (El País), José Miguelez (COPE), Amparo Estrada (Cinco Días), José Manuel Costas (ABC), Iñigo Saez de Ugarte (Cadena SER), a los que se irían incorporando más periodistas hasta llegar a una redacción de 140 personas. La plantilla de Público no estaba sobredimensionada en número de redactores si la comparamos con la mayoría de diarios de información general -en 2010 la plantilla llegó a estar próxima a las 180 personas frente a los 236 de La Razón, por ejemplo-, pero la masa salarial era muy 
elevada por el gran esfuerzo de dotarse de una redacción de alto nivel, estas son las razones por las que los gastos de personal siempre constituyeron un elemento importante de desequilibrio financiero.

Público logró reunir una redacción que podríamos considerar de alto rendimiento, algo que repercutiría en la buena calidad informativa del producto pero a un precio muy elevado, hasta el extremo que supondrían un lastre en los años en los que la recesión publicitaria se agudizó a partir del año 2008.

El estudio de Toni Cases y, en especial, el director de arte del periódico, Fernando Rapa Carballo, lograron un diseño muy visual que otorgó modernidad al periódico y que lograba una diferenciación importante con el resto de la competencia. Desde el principio se utilizó con eficacia la portada (diferenciándola de lo que sería una primera), el color y diferentes elementos infográficos.

El posicionamiento del diario Público cumplió muchas de las expectativas planteadas desde Mediapubli: lograron desarrollar en un tiempo muy breve un diario con capacidad de competir en la generación de noticias y opinión con diarios nacionales mucho más asentados, logró ocupar un posicionamiento ideológico claro en el que destacaba en su defensa de valores como el laicismo, la República, el cuestionamiento de la monarquía, los principios de la memoria histórica, los progresos de ciencia y la ecología, etc.

Se puede interpretar como un éxito del proyecto que el periódico consiguiese ocupar el espacio editorial y el posicionamiento ideológico que, desde un principio, había pretendido la propiedad y la dirección. El último Informe Anual de la Profesión Periodística incluye unos datos sobre la orientación política de los medios percibidos por las audiencias (1 más a la izquierda y 10 más a la derecha), y el diario Público es el que obtenía en 2011 la puntuación más significada a la izquierda con un 3,7; frente al 3,8 de La Sexta; el 3,9 de El País o el 4,0 de la Cadena Ser. (Farias, 2011)

Según un estudio de uso interno encargado por Mediapubli a la empresa demoscópica Obradoiro de Socioloxía, Público se había convertido en el diario referente para los votantes de la formación Izquierda Unida, un $27 \%$ de sus votantes declaraban comprar este diario, frente a un 16\% de los votantes del PSOE o un 7\% del PP. (Romero, 2010)

\subsection{Estructura organizativa}

La redacción logró mantener a lo largo de la existencia del periódico un bloque compacto, en contraste con los excesivos cambios que tuvieron lugar, tanto en la dirección como en la gestión del medio. La estructura organizativa inicial de Público contaba con la figura de un Director General, el periodista Juan Pedro Valentín, a la que se pretendía otorgar un papel importante como imagen visible del proyecto y puente o conexión entre la redacción y la propiedad de la empresa, entre los contenidos y la gestión, tratando de evitar así la llamada estructura bicéfala que se considera característica de muchas empresas informativas especialmente en el ámbito 
de los medios impresos. Sin embargo, las funciones directivas no colmaron las expectativas del periodista que abandonó el periódico en julio de 2008 para dirigir el canal de información 24 Horas de RTVE. David Torres asumiría la dirección general, y se encargaría de la gestión económica y operativa de la compañía, junto a Francisco Javier Múñoz Albenca (Director Gerente).

Posiblemente el mayor error en lo que se refiere a la estructura organizativa, se produjo con la contratación en febrero de 2008 de Ernesto Ekaizer como editor ejecutivo, un puesto que pretendía justificar el alto precio pagado para lograr el fichaje de uno de los periodistas estrellas de El País que ocupaba el cargo de adjunto a la dirección. La edición ejecutiva implicaba una revisión de los contenidos del diario, lo que generaría malestar y conflictos con el director del diario -Ignacio Escolar- y la mayor parte de redactores jefes que finalmente provocarían la salida de Ekaizer en octubre de 2008, con un alto coste para la empresa dado el blindaje de su contrato. A partir de ese momento la participación de Ekaizer en el diario se limitaría a sus columnas de opinión.

Público contó a lo largo de su corta historia con tres directores diferentes, sin duda demasiados cambios que provocarían un considerable efecto desestabilizador en la redacción. El director fundador fue Ignacio Escolar, que ocupó el puesto desde el 26 de septiembre de 2007 -si bien trabajaba desde meses antes en la configuración de la redacción y la preparación del periódico- hasta el 13 de enero de 2009. La apuesta por Escolar era arriesgada dada su juventud y falta de experiencia en un cargo de máxima responsabilidad en prensa escrita -había sido director adjunto de la Voz de Almería-. Sin embargo, Escolar representaba muchos de los valores que pretendía materializar el diario: renovación y compromiso. La etapa de Escolar fue muy importante en el diario, asentó las bases sobre las que se desarrollarían las diferentes secciones y muchos de los planteamiento editoriales. Una de sus apuestas personales fue la de no incluir editoriales dado que según sus propias declaraciones: "una sociedad mercantil no puede tener opinión sobre nada, las opiniones son de las personas físicas, no de las personas jurídicas, puesto que más que opiniones lo que tienen son intereses. No tendremos editoriales pero sí línea editorial." ${ }^{5} \mathrm{Su}$ experiencia previa en la comunicación en el ámbito de los blogs e Internet, resultó muy positiva para tratar de potenciar en el periódico la interacción con la audiencia y la integración de la versión digital y el papel. Escolar abandonó la dirección el 13 de enero de 2009, pero continuó hasta el cierre del periódico firmando una columna semanal. El propio periodista en su blog explicaba los motivos de su destitución: "los propietarios piensan que el nuevo director puede ser un revulsivo para mejorar las ventas que no son malas pero siempre se pueden mejorar" 6

\footnotetext{
${ }^{5}$ Ignacio Escolar "Todo lo que siempre quiso saber sobre Público" en Escolar.net 21-09-2007 Disponible en: http://www.escolar.net/MT/archives/2007/09/todo-lo-que-siempre-quiso-saber-sobrepublico.html [Fecha última consulta 05-05-2012]

${ }^{6}$ Ignacio Escolar "Mis respuestas sobre público" en Escolar.net 19-01-2009. Disponible en: http://www.escolar.net/MT/archives/2009/01/mis-respuestas-sobre-publico.html [Fecha última consulta 05-05-2012]
} 
La segunda etapa de Público estuvo dirigida por un periodista veterano procedente del diario El País y otros medios del grupo PRISA. Félix Monteira asumió la dirección el 14 de enero de 2009, y cesó cuando fue nombrado secretario de estado de comunicación en marzo de 2010. Monteira aportó experiencia, consolidó muchos de los contenidos del periódico, realizó diferentes ajustes y sobre todo trató de potenciar los temas de investigación -entre los que destacaron los trabajos de la periodista Alicia Gutiérrez que ha destapado diferentes asuntos de la trama Gurtel entre otros-.

La tercera y última etapa corresponde a la dirección de Jesús Maraña, desde el 4 de marzo de 2010 hasta el cierre del periódico el 24 de febrero de 2012. Maraña era el subdirector del periódico desde su fundación, y por tanto quizá sea el profesional que encarna mejor toda la historia del diario. Durante su dirección el diario obtuvo gran relevancia, y cierto liderazgo informativo, con el movimiento del 15 de marzo de 2011; también lograron importante repercusión nuevos temas de investigación destapados por el diario como gran parte del caso Urdangarin. En esta etapa el director tuvo que afrontar importantes dificultades al coincidir con los recortes y despidos de parte de la redacción, y varios meses de incertidumbre y tensión.

\subsection{Difusión, distribución y audiencia}

La evolución de la difusión de Público fue relativamente positiva, con un crecimiento del 24\% desde 2008 a noviembre de 2011, si bien todo el incremento de compradores se produce entre 2008 y 2010, dado que en ese año la difusión alcanza 87.168 ejemplares, y en 2011 incluso descendió a 87.058 (promedio difusión enero-noviembre 2011). A pesar de ese estancamiento la tendencia de la difusión de Público es positiva, comparada con el promedio de los diarios de información general, que en el mismo periodo perdieron cerca del $10 \%$ de su difusión. Si analizamos la estructura interna de las modalidades de esa difusión, comprobamos que la venta al número representaba el $55,2 \%$ del total de la difusión -por debajo del 62,7\% del promedio de todos los diarios de información general-, y que el número de venta en bloque constituía el 27,2\%, muy por encima del 9,5\% del promedio de la categoría. ${ }^{7} \mathrm{El}$ análisis identifica una debilidad de la venta en quioscos y un peso excesivo de la venta en bloque (suscripciones colectivas que no son enviadas al destinatario por el editor), una modalidad de distribución que constituye con mucha frecuencia un recurso de los editores para tratar de incrementar su difusión total, sin necesidad de mejorar su venta directa en quiosco. Por tanto, el modelo de crecimiento del diario se sustentaba en lo que algunos autores han calificado como "difusión dopada", una estrategia de obtener un rendimiento más rápido, pero que como efectos negativos genera desequilibrios económicos y desarrollos no sostenibles.

Público buscó convertirse en un medio con una importante difusión. Su modelo apostó por la distribución nacional en un intento de llegar al mayor número posible de puntos de venta, un sobreesfuerzo considerable pero sin lograr optimizar lo suficiente los gastos de aprovisionamientos, producción y distribución. El periódico contaba con

\footnotetext{
${ }^{7}$ Fuente Datos OJD 2007-2011
} 
cuatro ediciones diferentes: Madrid, Ciudades (Nacional), Cataluña y Andalucía; y para lograr una distribución radial se imprimía en siete rotativas localizadas en: Coslada -Madrid-, Barcelona, San Sebastián, Córdoba, Alicante, Las Palmas, Plasencia y Lugo. ${ }^{8}$ Los costes de distribución resultaban muy elevados y en muchos casos no se veían compensados con buenos resultados en determinadas zonas. La mayoría de lectores de Público se concentraban en núcleos urbanos. Cerca del $75 \%$ del total de difusión en 2010 se localizaba en Madrid $(26,4 \%)$, Cataluña $(13,6)$, Extremadura $(9,3)$, Andalucía $(9,2)$, Asturias $(8,8)$ y Navarra $(7,1)$. El 25\% restante se dispersaba en 11 Comunidades Autónomas diferentes. (AEDE, 2012)

La audiencia del diario tuvo un crecimiento del 77\% entre 2008 y 2012, una cifra muy notable. En 2008 tenía 169.000 lectores y llegaba a los 299.000 en 2011. ${ }^{9}$ El perfil del lector de Público era mayoritariamente masculino -incluso un poco por encima de la media de los diarios de información general- $62 \%$ de lectores frente a un $38 \%$ de lectoras. En cuanto a la edad, la horquilla de 25 a 54 años representaba el $42 \%$ del total de la audiencia, pero en comparación con el resto de diarios de información general el periódico logró incrementar ligeramente respecto a la competencia el número de lectores entre los 20 y los 34 años que llegaba al $25 \%$ del total de la audiencia frente a un $23 \%$ que se corresponde con la media del segmento de información general. El $75 \%$ de los lectores se podrían clasificar por ingresos económicos en las clases sociales media-media, media.-alta y alta. De nuevo comparando estas cifras con las medias de los diarios de información general encontramos que Público contaba con un mayor porcentaje de lectores de clase media-alta y alta, que representaban el $46,1 \%$ frente al $35 \%$ para el conjunto de diarios de información general. Un importante rasgo identificador de la audiencia de Público, claro reflejo de los datos vistos de difusión, es su localización en núcleos urbanos superiores a los 50 mil habitantes. El 65\% de sus lectores viven en este tipo de poblaciones frente a un $47 \%$ que representaba la cifra promedia para este tipo de prensa.

\subsection{Algunas razones de la inviabilidad económica del proyecto}

A falta de conocer las cuentas anuales del ejercicio 2011, el total de gastos de explotación de la empresa editora Mediapubli se situó en los ejercicios 2008, 2009, y 2010 por encima de los 50 millones de Euros, de los que entre los 37 y 38 millones correspondían a gastos de aprovisionamiento, una cantidad muy por encima de la que resultaría propia de un diario con su tirada y difusión. Otro dato interesante es la alta tasa de devoluciones que se producían del diario, por ejemplo en 2010 superaba el 34\% de los ejemplares distribuidos, unas cifras más propias de la prensa deportiva que de los diarios de información general, cuya media del segmento se aproxima al $21,7 \%$. Una desviación de tantos puntos implicaba un coste muy importante con impacto directo en la cuenta de resultados. El porcentaje de coste de consumos sobre ingresos por ventas en el conjunto de periódicos de información general en 2010, representaba el 59,22\%, en el caso de Público; el coste de aprovisionamientos superaba al importe de

\footnotetext{
${ }^{8}$ Noticias de la Comunicación n ${ }^{0} 296$, nov 2009, p.149

${ }^{9}$ Fuente Datos EGM 2008-2011
} 
los ingresos por ventas de ejemplares en un 48,1\%. El dato es muy revelador de lo insostenible del modelo de producción.

La cifra neta de negocio de Mediapubli en el periodo 2008-2010, creció más del 100\% al pasar de 20.802.000 euros a 40.560.000, pero siempre resultaron insuficientes para afrontar los gastos de explotación. La mala gestión comercial -delegada en exclusividad a la empresa del grupo Publiseis-,y la ya comentada contracción de la inversión publicitaria explica una proporción tan desequilibrada entre los ingresos por venta de ejemplares, que representaba en 2010 el 61\% de los ingresos totales y la venta de publicidad, que no llegaba al 39\%. Frente a un 58\% - 42\%, que era la proporción promedio para ese año del segmento de la información general. En el momento de la redacción de este trabajo no disponemos todavía de las cuentas anuales de 2011, es posible que en ellas se reflejen algunos efectos de los primeros recortes en gasto realizados por Mediapubli durante el periodo, aunque sin lograr cambios significativos en una manifiesta falta de rentabilidad.

En los tres ejercicios completos de los que disponemos datos, la empresa editora de Público generó 59 millones de euros de pérdidas, a las que habría que sumar las derivadas del ejercicio 2011, que diversas fuentes estiman en próximas a unos 20 millones de euros, por lo que la cifra total llegaría a los 80 millones de euros. ${ }^{10}$

El diario Público se sostuvo en estos dos últimos ejercicios, una vez su plan de negocio inicial resultó superado por la realidad, mediante recursos ajenos generando un excesivo endeudamiento.

No debemos olvidar que los años iniciales de cualquier proyecto empresarial, requieren de un tiempo hasta que el volumen de ingresos logra consolidarse y compensar los gastos de explotación. En el caso de la empresa editora de Público, se comprueba un incremento de la cifra neta de negocio de 20 millones de Euros en 2008 a cerca de 40 millones en 2010, pero la estructura de costes no permitía la rentabilidad. Con ese volumen de gasto para que la empresa pudiese pasar a números positivos, se necesitaría un incremento de los ingresos que con las perspectivas del mercado publicitario para 2012, no parecían poder producirse.

En 2011 la empresa trató de abaratar costes en diferentes partidas, entre ellas el personal con un ERE en noviembre que provocó una reducción de la plantilla en un $20 \%$-con anterioridad, a finales de 2009 ya se habían producido la salida de otros 19 trabajadores-. Los costes de impresión también se trataron de controlar reduciendo la paginación y otros gastos, pero el desequilibrio se seguía produciendo. El analista Juan Varela señalaba pocas fechas antes del cierre del periódico, y una vez declarado el 3 de enero de 2012 el concurso público de acreedores por parte de Mediapubli, la necesidad de reducir los costes de impresión y distribución, de apostar por el negocio digital, abandonar la idea de diario y convertirse en revista semanal y rebajar al menos en un

\footnotetext{
${ }^{10}$ Cuentas de resultados de Mediapubli Sociedad de Publicaciones y Ediciones S.L Fuente: Noticias de la Comunicación $\mathrm{n}^{\circ}$ 296, 317, 318
} 
$50 \%$ los costes, para estabilizarlos en unos 20 millones de euros como posibles soluciones para garantizar la viabilidad del periódico. ${ }^{11}$

\subsection{El cierre del papel y el legado digital de Público}

Roures y sus socios decidieron el cierre definitivo del diario el 24 de febrero de 2012, tras unos meses agónicos en los que los profesionales no dejaron de publicar ni un solo día el periódico, a pesar de la falta de cobro de sus nóminas y la incertidumbre sobre su futuro. Los lectores realizaron una campaña activa en la Red en apoyo del periódico, que alcanzó casi las 45.000 firmas de apoyo al manifiesto por la continuidad del diario. El balance de situación presentado en el concurso de acreedores, recogía la materialización de lo que había supuesto un fracaso de modelo de negocio y de gestión, con unos activos valorados por la administración concursal en 6.389.000 Euros, frente a un pasivo total reconocido de 22.117.000 Euros. ${ }^{12}$

Los empresarios pusieron el foco en explicar la quiebra por las malas condiciones del entorno, pero en ningún caso se realizó un análisis de los posibles problemas de gestión interna. En una rueda de prensa tras la decisión del cierre Jaume Roures apuntó a tres causas de la desaparición del periódico: "la crisis económica, la del papel frente al medio digital y la de la política de izquierdas en España (...) No esperábamos que la evolución tecnológica se comiera al papel tan rápidamente. Si hoy nos planteásemos sacar un periódico con millones de IPADs en el mercado, no lo haríamos, pero hace años no sabíamos que iba a ser así." 13 El último director del diario, Jesús Maraña, además de señalar las tres crisis: la económica, la publicitaria y la del papel "como factores decisivos que han hecho inviable el proyecto de Público", sí reconocía otros errores propios que se hubiesen podido cometer desde la dirección del periódico, o la empresa editora. ${ }^{14}$

La decisión del cierre del papel no incluía el cese de la versión digital del periódico. Un grupo de 20 trabajadores de Mediapubli continuaron con la edición de www.publico.es. La web en enero de 2012 alcanzó los cinco millones y medio de usuarios únicos según OJD -cifra que se había disparado ante la expectación provocada por los rumores del cierre del papel- y que en abril de 2012 -ya sin el posible apoyo de la versión impresa- se mantenía por encima de los 4,3 millones con un promedio de 281 mil navegantes únicos, una cifra sin duda más que interesante

\footnotetext{
11 Juan Varela "Un futuro para público" en Periodistas 21 (13-01-2012) Disponible en http://periodistas21.blogspot.com.es/2012/01/un-futuro-para-publico.html [Fecha última consulta 2004-2012]

12 Auto Judicial del Concurso Voluntario de Acreedores Mediapubli 14/2012. Juzgado Mercantil No9 Barcelona 11 de enero 2012

${ }^{13} \mathrm{http}: / /$ www.elperiodico.com/es/noticias/sociedad/jaume-roures-sobre-cierre-publico-han-caidootros-caeran-mas-1449722 [Fecha última consulta 03-05-2012]

14 Jesús Maraña "El papel de Público" en Buzón de voz blog de Jesús Maraña 24-2-2012 Disponible en http://blogs.publico.es/buzondevoz/972/el-papel-de-\%E2\%80\%98publico\%E2\%80\%99/ [Fecha última consulta 24-4-2012]
} 
para tratar de gestionar el legado digital de la marca Público. ${ }^{15}$ El 26 de abril Xarxa Integral de professionals $\mathrm{i}$ usuaris, una cooperativa integrada por trabajadores, extrabajadores y colaboradores de Público realizó una oferta de adquisición por valor de 240.000 euros con el compromiso de subrogación de 12 puestos de trabajo. Sin embargo, la administración concursal otorgaba el 23 de mayo a la empresa Display Connectors por un total de 412.000 euros -335.00 en efectivo y 77.000 en especie al asumir una serie de pagos sociales pendientes- la venta de la unidad productiva que incluía las cabeceras del negocio Mediapubli tanto en papel como en Internet. La sociedad compradora incluía en su oferta el compromiso de subrogación de los 21 puestos de trabajo que se mantenían desde febrero generando contenidos para la web del periódico. ${ }^{16}$

Display Connectors S.L., es una sociedad creada el 20 de febrero, cuyo capital social inicial compuesto por 15.000 euros se distribuye en un buen número de sociedades tras las que se encuentran Jaume Roures, Tatxo Benet y algunas otras personas que habían tenido relación directa con Mediapubli como Toni Cases y José Luis Zarraga. ${ }^{17}$ Roures y sus socios recuperaban de esta forma los derechos sobre sus cabeceras, no dispuestos a renunciar al valor que la marca Público habría alcanzado en el mercado informativo, con intención de relanzar la versión digital sin renunciar a posibles proyectos impresos en el futuro.

A pesar del rotundo fracaso empresarial del proyecto, el legado del diario Público y su posicionamiento editorial siguen siendo un referente para un buen número de lectores de izquierdas de prensa digital. Eso explica las diferentes iniciativas periodísticas que han surgido para tratar de recoger parte de esa herencia: además de la web oficial del periódico -publico.es- han surgido otros medios digitales con intención de convertirse en competencia directa. MasPublico.org, creado por un grupo de extrabajadores del periódico, pertenecientes a la cooperativa Xarxa, ha surgido con recursos muy limitados y con un futuro incierto respecto a su capacidad real de generar suficientes contenidos y tener continuidad en la red. Otra oferta más sólida es la de eldiario.es, nuevo proyecto periodístico del primer director del periódico Ignacio Escolar, en el que participan algunos periodistas y colaboradores de Público. El 28 de noviembre de 2012 el exdirector del diario Público Jesús Maraña anunciaba en Twitter la puesta en marcha de un nuevo medio informativo: Infolibre, "información libre e independiente", en el que también participan otros periodistas del desaparecido periódico junto a profesionales procedentes de El País y RTVE. Infolibre surge como un nuevo medio digital pero el proyecto también incluye la edición de una revista mensual en papel, Tintalibre. La web francesa Mediapart, fundada y dirigida por el periodista Edwy Plenel, será socia editorial de esta iniciativa de la que por el momento se desconoce su fecha de lanzamiento.

\footnotetext{
${ }^{15}$ Fuente: Datos OJD 2012

${ }^{16}$ Fuente Auto Judicial Venta Unidad Productiva Mediapubli. Juzgado Mercantil No9 Barcelona, 23 de mayo 2012

$17 \mathrm{http}: / /$ maspublico.org/display-connectors-la-inmobiliaria-de-roures/ [Fecha última consulta 4-62012]
} 
A pesar de la aparente abundancia de oferta informativa en la Red esta no siempre se traduce en una variedad y pluralidad real. Según señala el profesor Díaz Nosty, la audiencia de prensa digital en Internet tiende a una concentración natural en torno a los grandes diarios que logran una mayor capacidad de respuesta informativa. (Díaz Nosty, 2011) Por el momento es una incógnita si propuestas tan similares se podrán consolidar y obtener una audiencia internauta suficiente que les permita una cierta rentabilidad económica.

\section{CONCLUSIONES}

El caso del diario Público resulta de gran interés porque en su estudio confluyen algunos de los principales problemas con los que se ha enfrentado la prensa escrita en los últimos años. Con la perspectiva que ofrece el tiempo, podemos afirmar que el proyecto empresarial de este diario resultó asíncrono respecto a los procesos que el sector de la prensa ha experimentado desde el año 2007.

La iniciativa empresarial de Mediapubli -sociedad editora de Público- surgió como un intento por parte de Jaume Roures y sus socios de completar un gran grupo multimedia a partir de su fortaleza en el sector audiovisual. La expansión multimedia resultaba una característica común a las estrategias de las grandes corporaciones de comunicación en el inicio del siglo XXI. El lanzamiento de un diario de información general por parte de Mediapubli supuso un intento de aproximación a grupos referentes del sector de la comunicación en España como Prisa, Unidad Editorial y Vocento que contaban con diarios influyentes entre sus áreas de negocio. Estos tres grupos habían iniciado su actividad en el sector de la prensa-editorial para expandirse con posterioridad al ámbito audiovisual. La ruta seguida por Roures y sus socios era exactamente la inversa. La dura pugna que la empresa matriz Mediapro mantenía con el grupo PRISA en el ámbito del sector audiovisual en relación a la llamada "guerra del fútbol" parecía querer trasladarse a la prensa escrita, puesto que Público perseguía ganar lectores próximos al posicionamiento ideológico de El País. El periódico nace, por tanto, en un contexto en que las dos empresas confrontaban sus estrategias en diferentes mercados, sin olvidar las duras tensiones vividas entre ambas en el equilibrio de sus relaciones con el sistema político y el gobierno presidido por Rodríguez Zapatero (2004-2011).

Una constante identificada en el estudio del caso Público es precisamente su asincronía respecto a la evolución del sector de la comunicación. El intento de expansión multimedia de la empresa de Roures se intensificaba en el año 2007, precisamente el año en que se produce el gran punto de inflexión con el inicio de la dura crisis económica que modificaría las estrategias de crecimiento desarrolladas por las grandes empresas de comunicación en los años anteriores. El periodo 2007-2012 se ha caracterizado por duros ajustes y recortes que han implicado una reorganización de los negocios con las consiguientes estrategias empresariales constrictivas.

El proyecto empresarial del diario Público partía de un plan de viabilidad que se desarrollaba en un escenario totalmente diferente al que finalmente se enfrentó el 
periódico en sus poco más de cuatro años de existencia. El mercado de los diarios de información general en el año 2007 presentaba ya algunos problemas como sus dificultades para captar lectores menores de 35-40 años, la competencia de los diarios gratuitos y los nuevos medios digitales; si bien se mantenía cierta estabilidad en lo que se refiere a cifras generales de audiencia y difusión y un crecimiento importante de la facturación publicitaria. Sin embargo, el periódico se enfrentaría a un periodo muy recesivo en el sector, tanto en sus cifras de difusión como de facturación publicitaria que comprometerían más si cabe un proyecto empresarial cuyo éxito resultaba complejo incluso con circunstancias más favorables. A pesar de los cambios en los hábitos de lectura y de compra de diarios experimentados en los últimos años, el comprador de prensa mantenía en 2007 un alto grado de fidelidad a su cabecera de referencia que, junto con 1 estancamiento en las cifras de difusión previas al descenso experimentado a partir de 2008, suponía un reto extremadamente complejo para que un nuevo diario pudiese obtener una cifra de lectores y anunciantes suficiente para generar beneficios.

La apuesta más importante de Público pasaba por una cierta diferenciación del producto respecto a la competencia -que se intentaba realizar con un diseño rompedor y unos contenidos renovados y alternativos- que perseguía captar lectores descontentos de las líneas editoriales de periódicos asentados, especialmente del diario El País que presentaba la línea editorial más próxima en lo que se refiere al posicionamiento ideológico. El otro gran objetivo para aumentar cuota de mercado era seducir a lectores con un perfil más joven del comprador habitual de la prensa escrita, una tarea casi hercúlea ante la manifiesta preferencia de este colectivo por los medios digitales.

El proyecto de incursión en el mercado de la prensa escrita de Público confiaba en una cierta elasticidad del mercado de la demanda de diarios de información general, que en España se caracteriza por estructurarse a partir de posicionamientos editorialesideológicos. La oferta múltiple en el ámbito del centro-derecha de periódicos de tirada nacional (EL Mundo, ABC, La Razón, y posteriormente La Gaceta, o incluso otros medios regionales de importante difusión como La Vanguardia o El Correo) contrastaba con la presencia de El País como único diario de referencia en el centroizquierda.

A pesar de la gran influencia que las causas exógenas pudieron ejercer en el fracaso de Público, -que fueron utilizadas por sus propietarios como principales líneas argumentales del cierre de su edición en papel- no debemos olvidar otras causas endógenas que en muchos casos también se han caracterizado por una gran inadaptación respecto a la realidad del sector y a las propias características del producto y su audiencia.

La gestión económico-financiera del diario Público se basaba en una tasa de elevado crecimiento en lo que se refiere a difusión y facturación que implicaba una sobredimensionada estructura de costes. Volvemos a encontrar un nuevo elemento asincrónico en esta cuestión. La excesiva masa salarial generada por una política de 
contratación de profesionales de prestigio procedentes de otros medios, una mala gestión de la distribución en la que se optó por una distribución muy cara que perseguía llegar al mayor número de puntos de venta posible sin tener en cuenta la demanda real que el diario tenía en determinados ámbitos; así como una estrategia de marketing sustentada en una agresiva política de promociones que nunca obtuvieron la rentabilidad económica, generaron un proyecto interesante desde el punto de vista informativo pero económicamente insostenible.

Tampoco se lograron generar las sinergias que se podrían esperar por pertenecer a una gran corporación. Más bien al contrario, algunas de las interacciones que se generaron como la gestión comercial a través de la empresa Publiseis -muy alejada del sector de los anunciantes de prensa- y las compras internas de los productos audiovisuales, que protagonizaron gran parte de las promociones ya mencionadas, en lugar de favorecer más bien tuvieron un impacto negativo en la evolución de la cuenta de resultados de Mediapubli, empresa propietaria del diario.

La inestabilidad constante en lo que se refiere a su estructura organizativa, y en especial a la dirección del diario, tampoco contribuyeron de forma positiva al correcto rumbo del proyecto. Los excesivos cambios pusieron en evidencia las muchas dudas e inseguridades de unos propietarios que no conocían en profundidad el mercado de la prensa.

Este artículo ha señalado algunas de las posibles causas del cierre del diario Público pero también merecen ser destacadas las numerosas fortalezas y aciertos de esta aventura periodística. La apuesta por un diseño y unos contenidos novedosos, dentro de un sector sumido en el inmovilismo; o el logro de convertirse en una alternativa informativa a El País entre los lectores de izquierda, que si bien en la prensa de papel no ha resultado viable, en el ámbito de la prensa digital demuestra mantener su interés con el lanzamiento de diferentes proyectos "herederos" de su legado, constituyen éxitos periodísticos muy notables de un diario nacido a contracorriente de la evolución del sector.

\section{REFERENCIAS}

AEDE Libro blanco de la prensa diaria en España. Madrid: AEDE (2012) (2011) (2002)

Boczkowski, P. (2006). Digitalizar las noticias. Innovación en los diarios online. Buenos Aires: Manantial

Díaz Nosty, B. (2011). “La Crisis en la industria de la prensa. Vida más allá del papel”. En TELOS No 86, Enero - Marzo 2011, pp. 4-15.

Edo Bolós, C. (2005). "El éxito de los gratuitos hace más visible la crisis de la prensa diaria de pago". En Estudios del Mensaje Periodístico, n 11, pp. 23-44. 
Farias Batlle, P. (Dir.) (2001). APM Asociación de la Prensa de Madrid: Informe anual de la profesión periodística en España. Madrid: APM.

Farias Batlle, P. y Roses, S. (2009). "La crisis acelera el cambio del negocio informativo". En Estudios del Mensaje Periodístico, n 15, pp.15-32.

García Chamizo, F. (2009). El nacimiento de la Sexta. Análisis de una nueva estrategia competitiva de televisión "generalista". Director: Manuel Fernández Sande. Tesis Doctoral UCM: Madrid. Disponible en http://eprints.ucm.es/9583/1/T31301.pdf [Fecha última consulta 03-06-12].

INFOADEX Resumen estudio de la inversión publicitaria en España (2012). Disponible en http:/ / www.infoadex.es/RESUMEN\%202012.pdf [Fecha última consulta 05-06-12]

Larrañaga Rubio, J. (2009). "La crisis del modelo económico de la industria de los periódicos". En Estudios del Mensaje Periodístico, n 15 pp. 61-80.

Noticias de la Comunicación. Madrid, ISSN: 1130-8842

-(2011), n 318.

$-(2011), n^{\circ} 316$

$-(2010), n^{\circ} 307$

$-(2009), n^{\circ} 296$

Ramonet, I. (2005). "Medios de comunicación en crisis". En Le Monde Diplomatique. Enero. http://www.lemondediplomatique.cl/Medios-de-comunicacion-en-crisis.html [Disponible en 02-05-2012]

Rodríguez-Polo, X. R. y Martín-Algarra, M. (2011). “Los principios del sistema liberal de medios ante la crisis de la comunicación pública. Una aproximación crítica”. En Revista de Comunicación Vivat Academia, no 117. Madrid. Universidad Complutense, recuperado el 10 de Noviembre de 2012, en la siguiente dirección: http://www.ucm.es/info/vivataca/numeros/n117/PDFs/Varios3.pdf

Romero, J. (2010). La imagen de Izquierda Unida a través de tres medios de comunicación (2003-2008). Director Rueda Laffond. Investigación Diploma Estudios Avanzados UCM.

Salaverría, R. (2003). “Convergencia de medios". En Chasqui, n ${ }^{\circ}$ 81. Disponible en http://chasqui.comunica.org/81/salaverria81.htm Fecha última consulta en 28-5-12].

Sánchez, A. (2008). Los contenidos de los medios de comunicación. Calidad, rentabilidad y competencia. Barcelona: Ediciones Deusto. 


\section{Manuel Fernández Sande}

Licenciado y doctor en Periodismo por la Universidad Complutense de Madrid y licenciado en Documentación por la Universidad Carlos III de Madrid. Desde 2001 es profesor de grado y postgrado en la Facultad de Ciencias de la Información de la UCM. Autor, entre otras obras, de los libros Los orígenes de la radio en España I y II (Editorial Fragua 2005, 2006); ha publicado diversos capítulos y artículos en revistas y participa como ponente en numerosos congresos internacionales. Miembro de los grupos de investigación MediaComUCM y del internacional Midia Cultura e Memoria $(\mathrm{CNPq})$. Sus principales líneas de investigación son la gestión de las empresas de comunicación, el análisis del mercado radiofónico europeo y la historia de la radio. 